\title{
Urgensi Teknologi Informasi Sebagai Sarana Pendukung Guru di Era Digital
}

\author{
Wahyu Setiawan Saputa \\ Email: 1810111210014@mhs.ulm.ac.id \\ Program Studi Pendidikan Sejarah Fakultas Keguruan dan Ilmu Pendidikan \\ Universitas Lambung Mangkurat \\ Banjarmasin
}

\begin{abstract}
Abstrak
Inovasi merupaka sebuah perubahan yang merupakan hasil dari permikiran manusia, dengan pemikiran ini maka diharapkan adanya perubahan dalam pendidikan yang awalnya monoton. Dengan menggunakan teknologi informasi maka akan memudahkan guru dalam melakukan sebuah terobosan baru untuk melaksankan kegiatan melajar mengajar yang efektif. Karena pembelajaran yang efektif ini maka harusnya guru dapat membuat para muridnya menjadi individu yang cerdas.
\end{abstract}

\section{PENDAHULUAN}

Inovasi dapat diartikan sebagai sebuah perubahan kearah yang lebih baik, dan pendidikan adalah suatu kegiatan untuk mendapatkan ilmu pengetahuan baik di sekolah atau di luar sekolah. Inovasi pendidikan adalah sebuah perubahan untuk memecahkan masalah dalam pendidikan. Inovasi pendidikan adalah hal-hal yang berkaitan dengan komponen sistem pendidikan, entah dari arti sempit, yaitu tingkat lembaga pendidikan, ataupun arti luas, yaitu sistem pendidikan nasional (Rusdiana 2014). Inovasi pendidikan merupakan upaya dasar dalam memperbaiki aspek-aspek pendidikan dalam praktiknya (Jannah 2015)

Invention (invensi) adalah segala suatu penemuan yang baru dan belum ditemukan, dalam artiyan adalah hasil kreasi manusia. Sesuatu hal yang ditemui itu benar-benar belum ada, kemudian diadakan dengan hasil kreasi baru (Kristiawan et al. 2012). Inovasi (innovation) adalah suatu ide, barang, kejadian, metode yang dirasakan atau diamati sebagai suatu hal yang baru bagi seseorang atau sekelompok orang (masyarakat), baik itu 
berupa hasil invensi maupun diskoveri (Armiati 2018). Dari kedua penjelasan tadi, bisa kita simpulkan bahwa inovasi adalah sebuah hasil dari buah pemikiran masusia yang merupakan sebuah pembeharuan untuk membantu dan memecahkan masalah yang dihadapi manusia itu sendiri. Pendidikan juga melakukan inovasi untuk mempermudah dan memecahkan masalah-masalah yang ada di dalam dunia pendidikan di Indonesia.

Inovasi sangat penting bagi guru di era globalisasi saat ini karena perlunya sebuahperubahan dari guru untuk membuat siswa menjadi individu yang cerdas. Sebagai contoh guru dizaman dahulu lebih berfokus pada sisi hafalan berkaitan dengan serangkaian materi pembelajaran yang kadang dianggap tidak penting oleh siswa. Siswa juga dengan mudah melupakan materi yang telah mereka pelajari di dalam kelas (Anis et al. 2020).

\section{PERAN GURU SEBAGAI SEBUAH PROFESI}

Guru adalah jabatan profesional yang memilik tugas pokok yang amat menentukan dalam proses pertumbuhan dan perkembangan peserta didik (Gaffar 2007), hal ini dikarenakan seorang guru harus menempuh pendidikan agar menjadi seorang profesional. Dengan kurikulum saat ini yakni, kurikulum 2013 setidaknya guru berperan sebagai penyedia materi bukan sebagai sumber ajar, dan siswa dituntut lebih aktif dalam mencari dan mengolah materi sehingga pembelajaran lebih berfokus pada siswa. Setelah itu guru akan menilai siswa sebagai penilain sebagai hasil belajar. Setidaknya guru memberikan penilaian terhadap dua aspek saja yaitu, penilaian sikap dan penilaian pengetahuan (Effendi, Prawitasari, and Susanto 2021). Sebagai tenaga profesional seorang guru dituntut untuk bekerja dengan baik dan sesuai dengan kurikulum pendidikan sehingga dapat mewujudkan cita-cita pendidikan nasional yang dimana cita-cita tersebut adalah untuk mencerdaskan semua warga negara Indonesia.

Dalam bukunya yang berjudul "Profesi Keguruan" (Susanto 2020) menjelaskan bahwa kriteria seorang guru profesional adalah sebagai beriku.

"Seorang guru profesional minimal memiliki komitmen kepada peserta didikdan proses belajarnya, menguasai secara mendalam bahan pelajaran yang akan diajarkannya, serta cara penyampaiannya kepada siswa, bertanggung jawab memantau hasil belajar siswa melalui berbagai teknik evaluasi, mampu berpikir secara sistematis tentang apa yang dilakukan, mengadakan refleksi dan koreksi, belajar dari pengalaman dan memperhitungkan dampaknya pada proses belajar 
mengajar, dan seyogyanya merupakan bagian dari masyrakat belajar dalam lingkungan profesinya, sehingga menjadi interaksi yang luas dan profesional”.

Namun dengan semua permasalahan pendidikan yang terjadi di Indonesia guru diharapkan dapat mengatasinya. Lalu bagaimana guru mengatasinya? Dengan berbagai pelatihan dan pendidikan yang sudah ditempuh seorang guru diharapkan guru tersebut sudah matang dan menjadi tenaga profesional yang mempu mebuat sebuah inovasi baru dalam pendidikan, yang dimana inovasi ini bertujuan untuk menjawab semua permasalah di dunia pendidikan Indonesia. Contoh perubahan yang dapat kita lihat adalah perubahan metode dan model pembelajaran di sekolah zaman dahulu dengan zaman sekarang di Abad 21. Perubahan model dan metode sangat signifikan, yang awalnya model dan metodenya berfokus terhapat teacher center atau berpusat pada guru, yang dimana guru adalah sumber belajar dan tanpa adanya guru maka siswa tidak dapat mendapatkan materi pembelajaran. Akan tetapi, dizaman sekarang semua berubah menjadi student center atau semua kegiatan belajar mengajar berpusat kepada siswa, dari siswa yang melakukan diskusi tanya jawab, bahkan mencari materi untuk mendukung argumennya dengan berbagai sumber dan guru berperan sebagai fasilitator dan mediator yang berfungsi untuk mendukung semua kegiatan siswa dan akhirnya siswa dapat secara mandiri belajar hingga akhirnya mengerti dan memahami makna sebuah pembelajaran. Namun bukan berarti seorang guru lepas tangan begitu saja, tapi guru juga mengatur jalannya kegiatan belajar mengajar tersebut. Guru juga melakukan berbagai rencana pembelajaran untuk mendukung kegiatan belajar mengajar disekolah dengan cara memilih dan menggunakan metode yang sesuai dengan materi. Sehingga dengan perencanaan yang baik seorang guru dapat membuat suasana belajar di kelas yang kondusif dan idea sehingga guru tersebut dapat dikatakan sebagai seorang pekerja profesional karena berhasil menjalankan tugasnya yang sesuai dengan tuntutan kurikulum dan tujuan pendidikan nasional.

Ada banyak metode yang dapat digunakan pada saat ini, dan sebagai seorang calon guru sejarah saya bercermin dari dosen saya bahwa penggunaan model pembelajaran Pemikiran Sejarah (The Historical Thinking Learning Model) efektif dalam meningkatkan pengetahuan, sikap dan keterampila. Namun hal ini perlu mendapatkan dukungan terhadap 
infrastruktur, sumber daya pembelajaran, dan dukungan subjektif dalam MPBH terpenuhi (Anis et al. 2021).

Seorang guru harus dapat kreatif dan dapat berinovasi dalam pendidikan terlebih pada era digital saat ini. (Budiyono 2020) yang mengutip dari Wina Sanjaya (2010) mengungkapkan bahwa sebuah inovasi merupakan suatu ide, gagasan yang dilaksanakan dalam kurikulum dan pembelajaran yang dianggap baru untuk memecahkan masalah pendidikan. Beliau juga menjelaskan bahwa, mengajar bukan hanya sekedar menyampaikan materi pembelajaran tetapi juga pemberian bantuan terhadap siswa berupa penggunaan media pembelajaran. Dari sini bisa kita ketahui bahwa penggunaan media belajar sangat penting dalam pendidikan di era digital saat ini. Di zaman era digital saat ini penyampaian informasi dari guru kepada siswa tidak mesti harus melalui tatap muka, namun bisa menggunakan berbagai sosial media seperti Facebook, Instagram, Telegram dan lainnya. Selain itu dengan pemanfaatan yang baik, seorang guru juga dapat mengarahkan siswa-siswanya untuk mencari materi pembelajaran di Internet. Internet merupakan suatu media untuk berbagi informasi dan berinteraksi kapan dan dimana saja (Nurdin 2016). Oleh karena itu siswa dapat mendapatkan sumber belajar dari berbagai informasi d Internet. Hal ini berbeda sebelum era digital, yang mana sumber belajar siswa hanya guru dan buku.

Jadi dapat disimpulkan bahwa seorang guru yang profesional dapat membuat sebuah inovasi yang kreatif dengan memanfaatkan teknologi pendidikan di era digital saat ini. Karena dengan pemanfaatan teknologi pendidikan yang baik, guru dapat melakukan pembelajaran secara efektif dan maksimal. Dengan pembelajaran yang baik itu maka diharapkan kualitas pembelajaran menjadi lebih baik sehingga dapat tercapainya tujuan pendidikan nasional.

\section{GURU INDONESIA DAN TANTANGAN PROFESIONALISME}

Guru di Indonesia yang dituntut profesional di era globalisasi saat ini di tuntut untuk tidak buta teknologi atau gagap teknologi (gaptek). Di zaman serba teknologi ini seharusnya semua pekerjaan guru akan lebih dimudahkan ketimbang sebelum adanya teknologi, karena secara hakikat teknologi informasi berguna untuk membantu manusia. 
Seperti yang dijelaskan Van Dijk yang di kutip oleh (Febriani 2018) dalam jurnalnya menjelaskan bahwa ada 4 aspek dalam pemanfaatan teknologi informasi, aspek-aspek tersebut adalah:

1. Usage Time Usage time, adalah aspek waktu dalam pemanfaatan teknologi informasi. Namun fakta menunjukkan beberapa orang yang memiliki komputer di rumah sangat jarang dan bahkan sama sekali tidak pernah menyentuhnya. Artinya, teknologi belum dimanfaatkan secara optimal dari segi waktu. Seharusnya dengan teknologi yang dimanfaatkan dengan maksimal, maka pembelajaran dapat dilakukan kapan saja dan lebih mudah.

2. Usage Applications: Number and Diversity, adalah aspek pemanfaatan aplikasi teknologi informasi baik dari segi jumlah aplikasi maupun keragaman aplikasi. Dengan menggunakan berbagai aplikasi di Internet harusnya seorang guru harus memanfaatkan berbagai aplikasi untuk mendukung kegiatan pembelajaran. Seperti contoh pada saat pandemi saat ini penggunaan aplikasi seperti zoo, google meet, google classroom sangat membantu dalam kegiatan belajar secara daring.

3. Penggunaan perangkat akses terhadap internet, memberikan pengaruh yang kuat terhadap aspek lainnya seperti usage time dan usage application. Dengan menggunakan koneksi internet guru lebih mudah untuk mengakses informasi. Dengan internet tersebut maka guru terhindar dari biaya dan waktu dalam pencarian informasi dan bahan ajar tanpa batasan.

4. More or Less Active or Creative Use, adalah aspek penggunaan internet secara pasif, atau aktif dan inovatif. Penggunaan internet secara aktif dan kreatif adalah suatu tawaran konten internet oleh pengguna sendiri dimana hal ini masih merupakan fenomena yang bersifat minoritas meskipun terlepas dari keberadaan web yang menjanjikan serta kemunculan perspektif media yang menjanjikan. Artinya banyak hal yang bisa dilakukan oleh guru untuk menjadikan kegiatannya lebih produktif, kreatif dan inovatif. 
Kita ketahui bersama bahwa, tanpa bantuan teknologi maka pembelajaran akan sangat membosankan dan monoton, sehingga sangat penting penggunaan teknologi ini dalam kegiatan belajar mengajar di era digital ini. Diharapkan dengan bantuan teknologi informasi itu maka guru akan dimudahkan dalam mengajar dan dapat melakukan sebuah inovasi baru di dunia pendidikan di Indonesia pada abad ini. Dengan semua kemudahan itu, maka harusnya guru dapat memaksimalkan kualitas belajar mengajar dikelas agar siswa lebih mudah memahami pembelajaran.

Ada banyak berbagai inovasi dalam pendidikan yang memanfaatkan teknologi Informasi, salah contohnya adalah teknologi informasi berbasis web (internet). Dengan melaksanakan pembelajaran online yang menggunakan internet seperti contohnya Ruang Guru, Zenius dan Quipper, menjadi alternatif lain, karena siswa medapatkan informasi tambahan diluar pembelajaran di sekolahnya, selain itu pilihan model pembelajaran melalui internet seperti platform Edmodo dan Google Classroom semakin banyak digunakan dalam proses pembelajaran di sekolah (Yuliana 2019). Dengan menggunakan web seperti yang dijelaskan diatas guru dapat membuat inovasi dalam kegiatan belajar dikelas. Contoh dengan pemanfaatan web quizizz.com guru dapat melaksanakan UTS, Kuis, atau UAS dengan lebih atraktif dan membuat siswa lebih tertarik. Dengan menggunakan inovasi ini harapannya tingkat stress pada siswa akan lebih berkurang karena dengan kuis di quizizz.com memiliki lebih banyak warna sehingga secara psikis tidak membuat tegang dan lebih santai. Hal ini sangat berbeda dengan penggunaan soal-soal dikertas yang hanya ada warna hitam putih yang memberikan dampak psikis secara tidak langsung yang membuat siswa lebih tertekan dan mudah stress pada saat menjawab pertanyaan. Selain penggunaan web, penggunaan Aplikasi pembelajaran juga efektif yang dimana hal ini merupakan terobosan baru media belajar yang memberikan kebebasan mutlak bagi siswa mengoperasikannya(Susanto and Akmal 2018). Pengunaan aplikasi ini bisa digunakan untuk memberikan kemudahan guru untuk memberikan penjelasan tentang materi dengan mudah dan simpel, karena di dalam aplikasi sudah terdapat materi dan soal-soal tes.

Selain menggunakan Internet guru juga bisa menggunakan media film dokumenter untuk memeberikan materi, dengan memanfaatkan LCD proyektor pada saat ini membuat guru dapat melaksanakannya dengan mudah (Susanto, et al. 2021). Dengan menggunkan 
media film dokumenter pengajaran akan lebih efisien, karena di dalam film tersebut terdapat berbagai informasi yang dikemas dengan rapi dan membuat siswa mudah untuk memahami materinya.

\section{SIMPULAN}

Inovasi adalah sebuah perubahan dan pendidikan pun tidak lepas dari namanya inovasi, hal ini terjadi karena perkembangan zaman. Dengan berkembangnya zaman ke era digitan dan modern membuat banyaknya perubahan didalam pendidikan. Dengan banyaknya inovasi pendidikan sehingga pola dan metode pendidikan pun ikut berubah. Pendidikan yang awalnya hanya berfokus pada guru dan siswa hanya mendengarkan apa yang dikatakan oleh guru. Namun, dengan adanya teknologi informasi pola ini berubah menjadi pembelajaran yang berfokus kepada siswa. Maksud dari pembelajaran yang berfokus kepada siswa adalah siswa yang lebih aktif dalam kegiatan belajar mengajar karena siswa mampu memperoleh dan mengolah informasi diberbagai sumber diinternet dan guru hanya sebagai fasilitator dan pengawas dalam kegiatan belajar mengajar pada abad 21 sekarang ini.

Semua kegiatan belajar di era ini akan lebih mudah daripada era sebelumnya, karena di era sekarang guru dan siswa dapat memanfaatkan teknologi informasi untuk membantu kegiatan belajar mengajar, yang dimana dengan teknologi informasi ini membuat kegiatan belajar mengajar lebih efektif dan maksimal. Dengan bantuan teknologi informasi ini juga guru dapat melakukan inovasi ketika mengajar, seperti contohnya penggunaan web quizizz.com untuk melaksanakan kuis harian, UTS dan UAS. Yang mana dengan web ini guru tidak perlu lagi untuk memeriksa hasil jawaban satu persatu, namun semua sudah mendapatkan nilai secara otomatis dan hal ini sangat memudahkan guru.

Tuliskan simpulan dari semua pembahasan dari semua bagian di atas.

\section{REFERENSI}

\section{JURNAL :}

Anis, Mohamad Zaenal Arifin, Herry Porda Nugroho Putro, Heri Susanto, Karunia Puji Hastuti, and Mutiani. 2020. "Historical Thinking Model in Achieving Cognitive 
Dimension of Indonesian History Learning." PalAech's Journal of Archaeology of Egypt/ Egyptology 17(7):7894-7906.

Anis, Mohamad Zaenal Arifin, Heri Susanto, Sriwati, and Fitri Mardiani. 2021. "Analysis of the Effectiveness of MPBH: The Mains of Mandai as a Saving Food in Banjarmasin Community." Proceedings of the 2nd International Conference on Social Sciences Education (ICSSE 2020) 525(Icsse 2020):89-94. doi: 10.2991/assehr.k.210222.012.

Armiati. 2018. Inovasi Pendidikan Pembelajaran Ekonomi (Metode Pembelajaran Untuk Meningkatkan Hasil Belajar Ekonomi). Padang.

Budiyono. 2020. "Inovasi Pemanfaatan Teknologi Sebagai Media Pembelajaran Di Era Revolusi 4.0." Jurnal Kependidikan: Jurnal Hasil Penelitian Dan Kajian Kepustakaan Di Bidang Pendidikan, Pengajaran Dan Pembelajaran 6(2):300. doi: 10.33394/jk.v6i2.2475.

Effendi, Irfan, Melisa Prawitasari, and Heri Susanto. 2021. "IMPLEMENTASI PENILAIAN PEMBELAJARAN PADA KURIKULUM 2013 MATA PELAJARAN SEJARAH." Prabayaksa: Journal of History Education 1(1):21-25.

Febriani, riyono \&. Rahmi Dwi. 2018. "Pentingnya Pemanfaatan Teknologi Informasi Oleh Guru Bimbingan Dan Konseling.” Jurnal Wahana Konseling 1(2):74. doi: 10.31851/juang.v1i2.2092.

Gaffar, Mohammad Fakry. 2007. "Guru Sebagai Profesi." Jurnal Administrasi Pendidikan UPI 5(1).

Jannah, Fathul. 2015. "Inovasi Pendidikan Dalam Rangka Peningkatan Kualitas Pembelajaran Melalui Penelitian Tindakan Kelas.” Prosiding Seminar Nasional PS2DMP UNLAM 1(1):27-32.

Nurdin, Arbain. 2016. "Inovasi Pembelajaran Pendidikan Agama Islam Di Era Information and Communication Technology." TADRIS: Jurnal Pendidikan Islam 11(1):49. doi: 10.19105/tjpi.v11i1.971.

Susanto, Heri, and Helmi Akmal. 2018. "EFEKTIVITAS PENGGUNAAN APLIKASI PEMBELAJARAN BERBASIS MOBILE SMARTPHONE SEBAGAI MEDIA PENGENALAN SEJARAH LOKAL MASA REVOLUSI FISIK DI KALIMANTAN 
SELATAN PADA SISWA SEKOLAH MENENGAH ATAS Helmi Akmal Heri Susanto Abstrak PENDAHULUAN Era Abad Ke-21 Teknologi." Jurnal HISTORIA $6(2)$.

Susanto, Heri , Helmi Akmal, Irmawati, and Ersis Warmansyah Abbas. "Media Film Dokumenter Masuknya Islam Ke Nusantara dan Pengaruhnya Terhadap Keterampilan Berfikir Kritis Siswa." HISTORIA: Jurnal Program Studi Pendidikan Sejarah 9, no. 1 (2021).

Yuliana. 2019. "Inovasi Pembelajaran Melalui Teknologi Informasi: Pengembangan Model Pembelajaran Melalui Internet." Jurnal Isema: Islamic Educational Management 4(1):119-32. doi: 10.15575/isema.v4i1.5179.

\section{BUKU :}

Kristiawan, Muhammad, Irmi Suryanti, Muhammad Muntazir, Ribuwati, Ahmad Jon Areli, Mediarita Agustina, Rosda Fajri Kafarisa, Agus Guntur Saputra, Nani Diana, Evi Agustina, Ririn Oktarina, and Tita Bela Hisri. 2012. Inovasi Pendidikan. Pertama. edited by Wade Group. Ponorogo: Wade Group.

Rusdiana. (2014). Konsep inovasi pendidikan (M. M. Dr. H. A. Rusdiana (ed.); Pertama). CV. PUSTAKA SETIA.

Susanto, Heri. 2020. Profesi Keguruan. edited by B. Subiyakto and H. Akmal. Banjarmasin: Program Studi Pendidikan Sejarah Fakultas Keguruan dan Ilmu Pengetahuan Universitas Lambung Mangkurat. 